\title{
POTENSI PEMBANGKIT LISTRIK TENAGA MIKROHIDRO TURBIN KAPLAN DENGAN VARIASI DEBIT AIR
}

\author{
Didik Sugiyanto $^{1 \mathrm{a}}$, Tugimin $^{2 \mathrm{~b}}$ \\ ${ }^{1}$ Universitas 17 Agustus 1945 Jakarta \\ ${ }^{a}$ Jl. Sunter Permai Raya, Sunter Agung Podomoro Jakarta Utara, 14350 \\ ${ }^{2}$ Universitas Muhammadiyah Surakarta \\ J1. A. Yani Tromol Pos 1, Pabelan Kartasura, Jawa Tengah 57102 \\ email: didiksgy@gmail.com, bejost@yahoo.com
}

\begin{abstract}
ABSTRAKSI
Dalam rancang bangun turbin Kaplan perlu di perhatikan besar kecilnya debit air serta heat statis.Tujuannya adalah merancang bangun turbin Kaplan dengan ketinggian $4 m$ dengan debit $0.025 \mathrm{l} / \mathrm{s}$ dengan sudu rotor $30^{\circ}$ dan sudu stasioner $30^{\circ}$.Selanjutnya hasil rancang bangun turbin Kaplan di uji unjuk kerjanya.

Pengujian turbin Kaplan dilakukan engan menggunakan empat buah pompa air.untuk mendapatkan debit air $17.676 \mathrm{l} / \mathrm{s}, 26.514 \mathrm{l} / \mathrm{s}, 35.352 \mathrm{l} / \mathrm{s}$ dan ketingian heat statis $4 \mathrm{~m}$ selanjutnya mengukur putaran turbin setiap pergantian debit air dengan tachometer.

Hasil rancang bangn turbin Kaplan didapatkan diameter luar sudu turbin 0,138m, diameter tengah sudu turbin 0,095m dan diameter tengah sudu turbin $0,057 \mathrm{~m}$, sementara itu hasil dari pengujian turbin Kaplan dengan sudu rotor $30^{\circ}$ dan sudu stasioner $30^{\circ}$ Putaran tertinggi yang dihasilkan oleh Turbin Kaplan ini ada pada debit 35,352 l/s yaitu pada putaran $503 \mathrm{rpm}$. Putaran terendah yang dihasilkan oleh Turbin Kaplan ini, ada pada debit 17,676 l/s yaitu pada putaran136 rpm.
\end{abstract}

Kata kunci: turbin kaplan, sudu, debit

\section{PENDAHULUAN}

\section{A. Latar Belakang Masalah}

Peningkatan kebutuhan energi listrik oleh masyarakat dan dunia industri tidak sebanding dengan peningkatan produksi listrik oleh PLN. Data kementrian ESDM tahun 2009 menunjukan rasio elektrifikasi atau perolehan tenaga listrik secara nasional baru mencapai sekitar $65 \%$.

Pasokan energi pada pusat-pusat pembangkit listrik saat ini masih mengandalkan energy berbas is fosil seperti minyak bumi, gas dan batu bara. Pemerintah melalui kementrian energy dan sumber daya mineral (ESDM) mengarahkan kebijakan pemanfaatan energil baru terbarukan seperti air sungai angin, biomassa dan surya sebagai sumber energy listrik skala kecil masa depan.

Indonesia merupakan wilayah beriklim tropis dengan curah hujan cukup tinggi serta memiliki topologi bergunung-gunung dengan mata air dan sungai-sungai yang mengalir 
sepanjang tahun, . sungai-sungai ini sangat potensial untuk digunakan sebagai sumber energi pembangkit listrik tenaga mikrohidro (PLTMH)

Terutama didaerah yang memiliki banyak terjunan pembangunan PLTMH yang memanfaatkan aliran sungai diyakini dapat mengatasi krisis kistrik yang hingga kini blum teratasi

Data kementrian ESDM menunjukan bahwa potensi tenaga air (hydropower) menempati posisi tertinggi pada pemanfaatan energy barut terbarukan yaitu 4200 MW air terjun alami ,sungai dan saluran irigasi teknis merupakan potensi yang sebesar 459 MW. Potensi energin sebesar ini jika di dayagunakan sebagai penggerak mula PLTMH tentu akan mempercepat peningkatan pertumbuhan rasio elektrifikasi nasonal .Pembangunan dan pengembangan PLTMH di desa-desa yang dilalui sungai masih terbuka luas.

Seperti yang terjadi pada Desa Nogosaren, Kecamatan Getasan, Kabupaten Semarang yang masih mengalami kendala dalam hal kelistrikan, terutama untuk menaikkan air bersih dengan pompa air dari sumber air ke pemukiman.Data yang diperoleh dari daerah tersebut adalah Heat statis (H) $4 \mathrm{~m}$ debit (Q) $0,025 \mathrm{~m} 3 / \mathrm{s}$

Rumusan masalah dalam penelitian ini adalah bagaimana desain dan konstruksi Turbin Kaplan dengan Q 0,025 m³. $\mathrm{s} 4 \mathrm{~m}$

Adapun tujuan dalam penelitian ini adalah:

1. Bagaimana desain dan konstruksi Turbin Kaplan pada ketinggian (H) $4 \mathrm{~m}$ dan Q 0,025 $\mathrm{m} 3 / \mathrm{s}$.

2. Pengujian unjuk kerja Turbin Kaplan dg sudu rotor $30^{\circ}$ dan sudu stasioner $30^{\circ}$ dengan variasi debit air,17,676 1/s, 26,514 1/s dan 35,352 1/s

Pengembangan turbin air sebagai pembangkit listrik akan memberikan kontribusi pada pasokan energi nasional. Air adalah energi terbaharukan sehingga persediaannya melimpah. Energi air juga ramah lingkungan sehingga pemanfaatannya meminimalisir kerusakan lingkungan.

Pemanfaatan turbin air di daerah tersebut dapat membantu mengem-bangkan potensi daerahnya karena ketersediaan sumber energi alternatif berarti terbukanya kesempatan yang lebih besar untuk memanfaatkan teknologi dalam rangka menunjang kemajuan daerah.

Batasan masalah dalam kegiatan perancangan dan pembuatan turbin air ini adalah:

1. Turbin kaplan

2. Untuk mendapatkan output berupa data putaran turbin dengan berdasarkan variabel pemilihan pada sudut sudu rotor $30^{\circ}$ dan sudu stator $30^{\circ}$, dengan variasi debit : 17,676 1/s, 26,514 1/s dan 35,352 1/s

\section{TINJAUAN PUSTAKA}

\section{A. Kajian Pustaka}

Sahid (2006) menyatakan bahwa perbubahan bentuk penampang nosel berpengaruh terhadap unjuk kerja turbin pleton mikro. Nozel berpenampang lingkaran menghasilkan daya dan efisiensi yang paling rendah sebelum mencapai kondisi optimum, untuk input energy aliran yang sama. Nozel pernampang segi empat dengan rasio panjang dan lebar, $\mathrm{R}=1$ memiliki karakteristik daya dan efisiensi yang paling baik dibanding penampang yang lain. Daya dan efisiensi maksimum yang bisa dibangkitkan turbin dengan nozel berpenampang 
segi empat $\mathrm{R}=1$ adalah 440,0 watt dan 79,3\% meningkat 18,4\% dibandingkan dengan nosel berpenampang lingkaran.

\section{B. Dasar Teori}

Turbin Kaplan dapat beroperasi pada kecepatan tinggi sehingga ukuran roda turbin lebih kecil dan dapat dikopel langsung dengan generator.

Menurut Bernoulli apabila air dialirkan dalam pipa dari ketinggian tertentu dan selisih ketinggian antara permukaan atas dan bawah adalah $\mathrm{z}$ dan tidak terdapat energi yang masuk atau keluar, maka besar energi yang dikandung oleh air tersebut adalah: Dietzel, F (1988).

$$
W=m \cdot g \cdot z+m \frac{P}{\rho}+m \frac{c^{2}}{2}
$$

dengan:

$\mathrm{W}=$ Energi yang dikandung air $\quad(\mathrm{Nm})$

$\mathrm{m}=$ zat cair $(\mathrm{kg})$

$\mathrm{g}=$ Gravitasi bumi $\quad(\mathrm{m} / \mathrm{s} 2)$

$\mathrm{Z}=$ Ketinggian suatu tempat yang dipakai sebagai standar $(\mathrm{m})$

$\mathrm{P}=\operatorname{Tekanan}\left(\mathrm{N} / \mathrm{m}^{2}\right)$

$\rho=$ Massa jenis zat cair $\left(\mathrm{kg} / \mathrm{m}^{3}\right)$

$\mathrm{c}=$ Kecepatan aliran zat cair $(\mathrm{m} / \mathrm{s})$

\section{Pemilihan Jenis Turbin}

Jenis turbin yang digunakan sangat tergantung dari besarnya debit air (Q) dan tinggi jatuh air yang tersedia, besarnya harga dari debit dan tinggi jatuh air ini didapat dari hasil survey ke lapangan. Secara teoritis dalam perencanaan pemilihan jenis turbin ditentukan berdasarkan kecepatan spesifik (nq), karakteristik turbin dan debit serta tinggi jatuh air efektif (He).

\section{Pemilihan Jenis Turbin Berdasarkan Kecepatan Spesifik}

$$
\mathrm{n}_{\mathrm{q}}=\frac{n \sqrt{\mathrm{Q}}}{\mathrm{H}^{0,75}}
$$

\section{Dimana :}

$\mathrm{Q}=$ Debit air yang dibutuhkan $\quad(\mathrm{m} 3 / \mathrm{s})$

$\mathrm{H}=$ tinggi jatuh air effektif

$\mathrm{n}=$ Kecepatan putaran turbin (rpm)

\section{Perbandingan Karakteristik Turbin}

Perbandingan karakteristik turbin dapat kita lihat pada grafik head (m) dengan flow $\left(\mathrm{m}^{3} / \mathrm{s}\right)$ di bawah ini. 


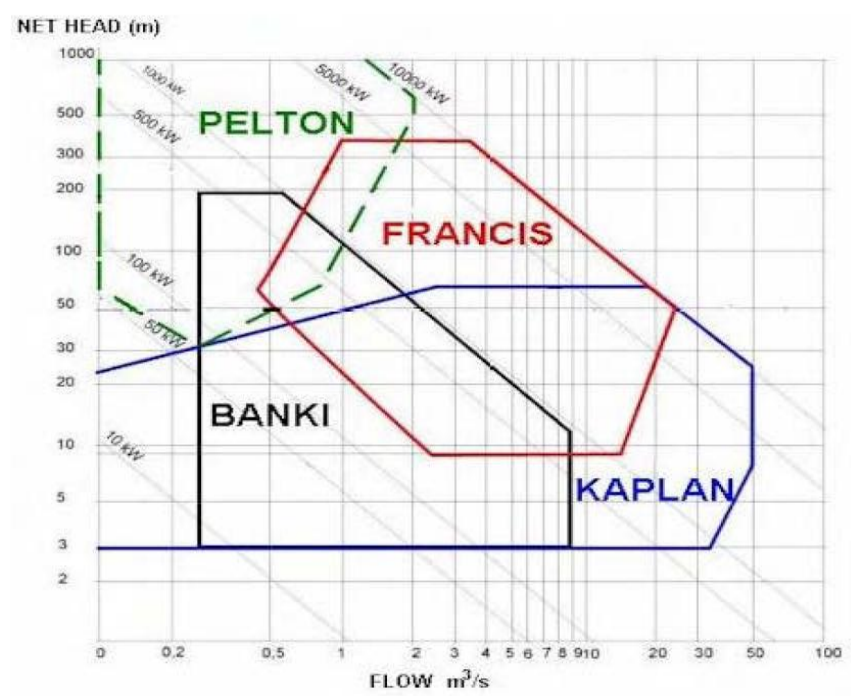

Keterangan :

Daerah dengan garis biru mempresentasikan Turbin Kaplan

Daerah dengan garis merah mempresentasikan Turbin Francis

Daerah dengan garis hijau mempresentasikan Turbin Pelton

Daerah dengan garis hitam mempresentasikan Turbin Crossflow

\section{Pemilihan Jenis Turbin Berdasarkan Debit dan Head}

Debit air merupakan hal yang sangat menentukan dalam perencanaan turbin air, karena daya yang dihasilkan oleh turbin sangat tergantung pada debit air yang tersedia. Menurut persamaan kontinuitas debit air yang mengalir dalam pipa bertekanan dapat ditentukan dengan persamaan:

$\mathrm{Q}=\mathrm{V}$. A

dimana:

$\mathrm{Q}=$ Debit air $\quad\left(\mathrm{m}^{3} / \mathrm{s}\right)$

$\mathrm{V}=$ Kecepatan aliran air $\quad(\mathrm{m} / \mathrm{s})$

$\mathrm{A}=$ Luas penampang pipa

\section{Pemilihan Turbin Berdasarkan Head}

Yang dimaksud dengan tinggi jatuh air efektif adalah tinggi jatuh air aktual dikurangi total kerugian energi (Head losses) disepanjang saluran. Dalam persamaan 10 dapat dinyatakan :

$H_{s}=H_{a}-\Sigma H I$

dimana:

$\mathrm{He} \quad=$ Tinggi jatuh air efektif $\quad(\mathrm{m})$

$\mathrm{Ha}=$ Tinggi jatuh air actual $\quad(\mathrm{m})$

$\mathrm{Hl}=$ Head losses

Aplikasi penggunaan turbin berdasarkan tinggi head yang didapatkan adalah sebagai berikut ini :

1) Turbin Kaplan : $2<\mathrm{H}<100$ meter

2) Turbin Francis : $5<\mathrm{H}<500$ meter

3) Turbin Pelton : $\mathrm{H}<30$ meter

4) Turbin Banki : $2<\mathrm{H}<200$ meter 
Kecepatan Spesifik $\left(\mathbf{n}_{\mathbf{q}}\right)$

$\mathrm{n}_{\mathrm{q}}=\frac{n \sqrt{\mathrm{Q}}}{\mathrm{H}^{0,75}}$

dimana :

$\mathrm{n}_{\mathrm{q}} \quad=$ kecepatan spesifik $\quad(\mathrm{rpm})$

$\mathrm{H} \quad=$ tinggi air jatuh $\quad(\mathrm{m})$

$\mathrm{Q} \quad=$ debit aliran $\quad(\mathrm{m} 3 / \mathrm{s})$

\section{Kecepatan Keliling Turbin (U)}

- Kecepatan Keliling Bagian Luar Sudu $\left(u_{L}\right)$

$\mathrm{u}_{\mathrm{L}}=\mathrm{u} 1^{*}$. Co.

dimana :

$u_{L}{ }^{*}=$ faktor kecepatan keliling bagian luar sudu

$\mathrm{Co}=\sqrt{2 . \mathrm{g} \cdot \mathrm{H}}$ $(\mathrm{m} / \mathrm{s})$

- Kecepatan Keliling Bagian Leher Poros Sudu $\left(u_{N}\right)$

$\mathrm{u}_{\mathrm{N}}=\mathrm{u}_{\mathrm{N}}^{*} \cdot \mathrm{c}_{0}$

dimana:

$\mathrm{u}_{\mathrm{N}}^{*}=$ faktor kecepatan keliling bagian leher poros sudu

Kecepatan Keliling Bagian Tengah Sudu (uM)

$\mathrm{u}_{\mathrm{M}}=\frac{u_{L}-u_{N}}{2}$

\section{Diameter Turbin (D)}

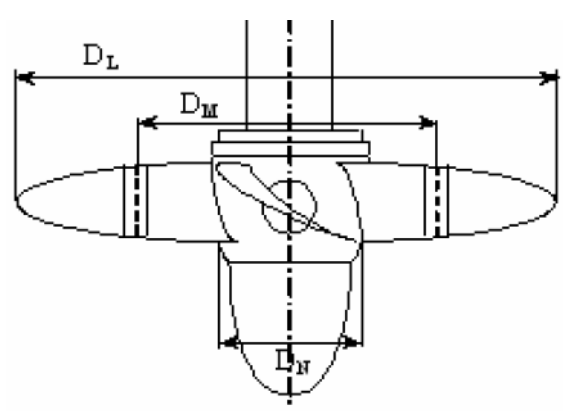

Gambar 1. Sket Turbin Kaplan

Diameter Luar Sudu Turbin (DL)

$\mathrm{D}_{\mathrm{L}}=\frac{60 \cdot u_{L}}{\pi \cdot n}$

dimana :

$\mathrm{uL}=$ kecepatan keliling bagian luar sudu $(\mathrm{m} / \mathrm{s})$

$\mathrm{n}=$ kecepatan putar turbin (rpm) 


\section{Diameter Leher Poros Sudu Turbin (DN)}

$\mathrm{D}_{\mathrm{N}}=\frac{60 \cdot u_{N}}{\pi \cdot n}$

dimana :

$\mathrm{u}_{\mathrm{N}}=$ kecepatan keliling bagian leher poros $(\mathrm{m} / \mathrm{s})$

$\mathrm{n}=$ kecepatan putar turbin (rpm)

Diameter Tengah Sudu Turbin (DM)

$\mathrm{D}_{\mathrm{M}}=\frac{D_{L} \cdot D_{N}}{2}$

dimana :

$\mathrm{DL}=$ diameter leher poros sudu turbin $(\mathrm{m})$

$\mathrm{DN}=$ diameter leher poros sudu turbin $(\mathrm{m})$

\section{Segitiga Kecepatan}

Kecepatan Aliran $\left(\mathbf{V}_{\text {air }}\right)$

$\mathrm{V}_{\text {air }}=\frac{\mathrm{Q}}{\mathrm{A}}$

dimana :

$\mathrm{Q}=$ debit aliran $\left(\mathrm{m}^{3} / \mathrm{s}\right)$

$\mathrm{A}=$ luas penampang $(\mathrm{mm})$

$A=\frac{D_{L}^{2}-D_{N}^{2}}{R} \cdot \pi$

\section{Profil Sudu}

Pada profil sudu mempunyai kemiringan $\delta$ yang kecil, sudut kemiringan $\delta$ adalah sudut yang dibentuk oleh aliran $W_{\infty}$ dengan kemiringan $\beta \infty$ dan diantara $\beta_{1}$ dan $\beta_{2}$ terdapat suatu lengkungan kecil

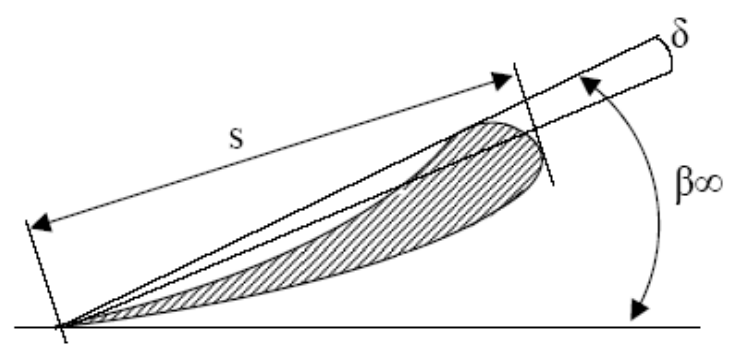

Gambar 2. Sket Profil Sudu

dimana:

$\delta$ = sudut kemiringan

$$
=\frac{\zeta \mathrm{a}-4 \cdot \mathrm{Y}_{\max } / \mathrm{S}}{0,092} \text {. }
$$

$\mathrm{Y}_{\max }=$ tebal profil

$$
=\left(\frac{\mathrm{s} . \zeta \mathrm{a}}{4}\right)-(0,092 . \delta)
$$


$\mathrm{s} \quad=$ panjang profil

$\zeta \mathrm{a} \quad=$ tahanan profil

$\zeta \mathrm{a} \frac{\mathrm{s}}{\mathrm{t}}=2 \frac{\Delta \mathrm{Cu}}{\mathrm{w} \infty}$

$\zeta a . s / t$ dikenal sebagai faktor pembebanan, harga s/t (panjang tali busur/ pembagian sudu) dipilih sampai dengan harga 1,4. Dengan demikian $\zeta$ a dapat dihitung.

- Profil sudu bagian luar

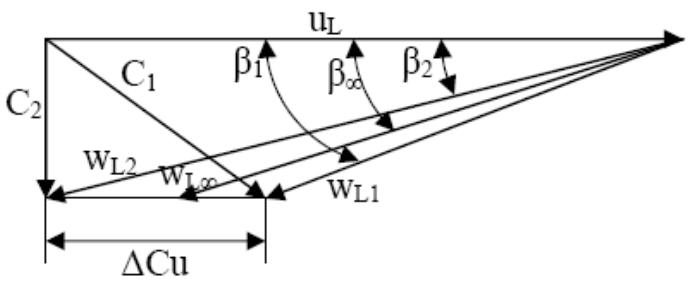

Gambar 3. Segitiga kecepatan bagian luar

Koefisien gaya angkat/ tahanan profil [ $\zeta \mathrm{a}]$

$\zeta \mathrm{a} \frac{\mathrm{s}}{\mathrm{t}}=2 \frac{\Delta \mathrm{Cu}}{\mathrm{w} \infty}$

Dimana s/t diambil harga 1,2

Dari grafik pemasangan sudut dan tahanan profil diperoleh $\delta$

$\mathrm{t}=\frac{\mathrm{D}_{\mathrm{L}} \cdot \pi}{\mathrm{z}}$

Tebal profil [ $\left.\mathrm{Y}_{\max }\right]$

$\mathrm{Y}_{\max } \quad=\left(\frac{\mathrm{s} . \zeta .}{4}\right)-(0,092 . \delta)$

- Profil sudu bagian tengah

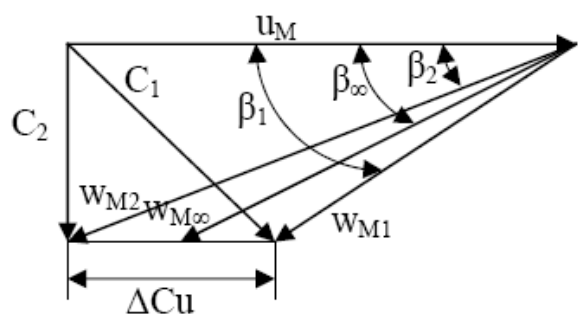

Gambar 4. Segitiga kecepatan bagian tengah

Koefisien gaya angkat/ tahanan profil [ $\zeta a$ ]

$\zeta \mathrm{a} \frac{\mathrm{s}}{\mathrm{t}}=2 \cdot \frac{\Delta \mathrm{Cu}}{\mathrm{w} \infty}$

dimana s/t diambil harga 1,2

Dari grafik pemasangan sudut dan tahanan profil diperoleh $\delta$

Panjang profil [s]

$\mathrm{s} / \mathrm{t}=1,2$ 
dimana:

$\mathrm{t}=\frac{\mathrm{D}_{\mathrm{M}} \cdot \pi}{\mathrm{z}}$

Tebal profil $\left[\mathrm{Y}_{\max }\right]$

$\mathrm{Y}_{\max }=\left(\frac{\mathrm{s} . \zeta .}{4}\right)-(0,092 . \delta)$

\section{Profil sudu bagian leher poros}

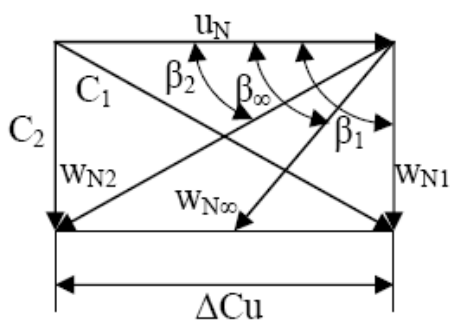

Gambar 5. Segitiga kecepatan bagian leher poros

Koefisien gaya angkat/ tahanan profil [ $\zeta \mathrm{a}$ ]

$\zeta \mathrm{a} \cdot \frac{\mathrm{s}}{\mathrm{t}}=2 \cdot \frac{\Delta \mathrm{Cu}}{\mathrm{w} \infty}$

dimana s/t diambil harga 1,2

Dari grafik pemasangan sudut dan tahanan profil diperoleh $\delta$

Panjang profil [s]

$\mathrm{s} / \mathrm{t}=1,2$

dimana:

$\mathrm{t}=\frac{\mathrm{D}_{\mathrm{N}} \cdot \pi}{\mathrm{z}}$

Tebal profil [ $\left.\mathrm{Y}_{\max }\right]$

$\mathrm{Y}_{\max }=\left(\frac{\mathrm{s} . \zeta .}{4}\right)-(0,092 . \delta)$

\section{Daya Turbin $\left[\mathbf{P}_{\mathrm{T}}\right]$}

$\mathrm{P}_{\mathrm{T}} \quad=\mathrm{Mt} . \omega$.

dimana:

Mt = momen putar

$=\mathrm{Ft} \cdot \mathrm{r}$

$\mathrm{Ft} \quad$ gaya tangensial

$=\mathrm{D}_{\mathrm{M}} \cdot \pi \cdot \mathrm{B} \cdot \mathrm{V} \cdot \rho\left(\mathrm{W}_{\mathrm{u} 2}-\mathrm{W}_{\mathrm{u} 1}\right)$

$\mathrm{r} \quad=$ jari-jari leher poros suhu

$\omega \quad=$ kecepatan sudut 
$\omega=\frac{\pi \cdot n}{30}$
$B=\frac{\left(D_{t}-D_{N}\right)}{2}$

Gaya Aksial [W]

$\mathrm{W}=\left(\frac{\rho}{2}\right) \cdot\left(\mathrm{w}_{2}^{2}-\mathrm{w}_{1}^{2}\right) \cdot \mathrm{D} \cdot \pi \cdot \mathrm{B}$

dimana:

$\mathrm{W}=$ gaya aksial $[\mathrm{N}]$

$\rho \quad=$ rapat air $\left[1000 \mathrm{~kg} / \mathrm{m}^{3}\right]$

$\mathrm{w}_{2}=$ kecepatan relatif aliran terhadap sudu jalan $[\mathrm{m} / \mathrm{s}]$

$\mathrm{w}_{1}=$ kecepatan relatif aliran terhadap sudu pengarah $[\mathrm{m} / \mathrm{s}]$

$\mathrm{D}=$ diameter tengah sudu $[\mathrm{m}]$

B = jumlah lebar seluruh sudu [m]

\section{Efisiensi $\left[\eta_{t}\right]$}

$\eta_{\mathrm{t}} \quad=\frac{\mathrm{P}_{\mathrm{d}}}{\text { H.Q.p.g }}$.

dimana:

$\eta_{\mathrm{T}} \quad=$ efisiensi turbin [\%]

$\mathrm{P}_{\mathrm{d}} \quad$ = daya yang transmisikan turbin $[\mathrm{kW}]$

$\mathrm{H} \quad$ = tinggi air jatuh $[\mathrm{m}]$

$\mathrm{Q}=$ debit aliran $\left[\mathrm{m}^{3} / \mathrm{s}\right]$

$\mathrm{g} \quad=$ percepatan gravitasi $\left[\mathrm{m} / \mathrm{s}^{2}\right]$

$\rho \quad=$ kerapatan air $\left[\mathrm{kg} / \mathrm{m}^{3}\right]$ 


\section{METODOLOGI PENELITIAN}

\section{A. Diagram Alir Penelitian}

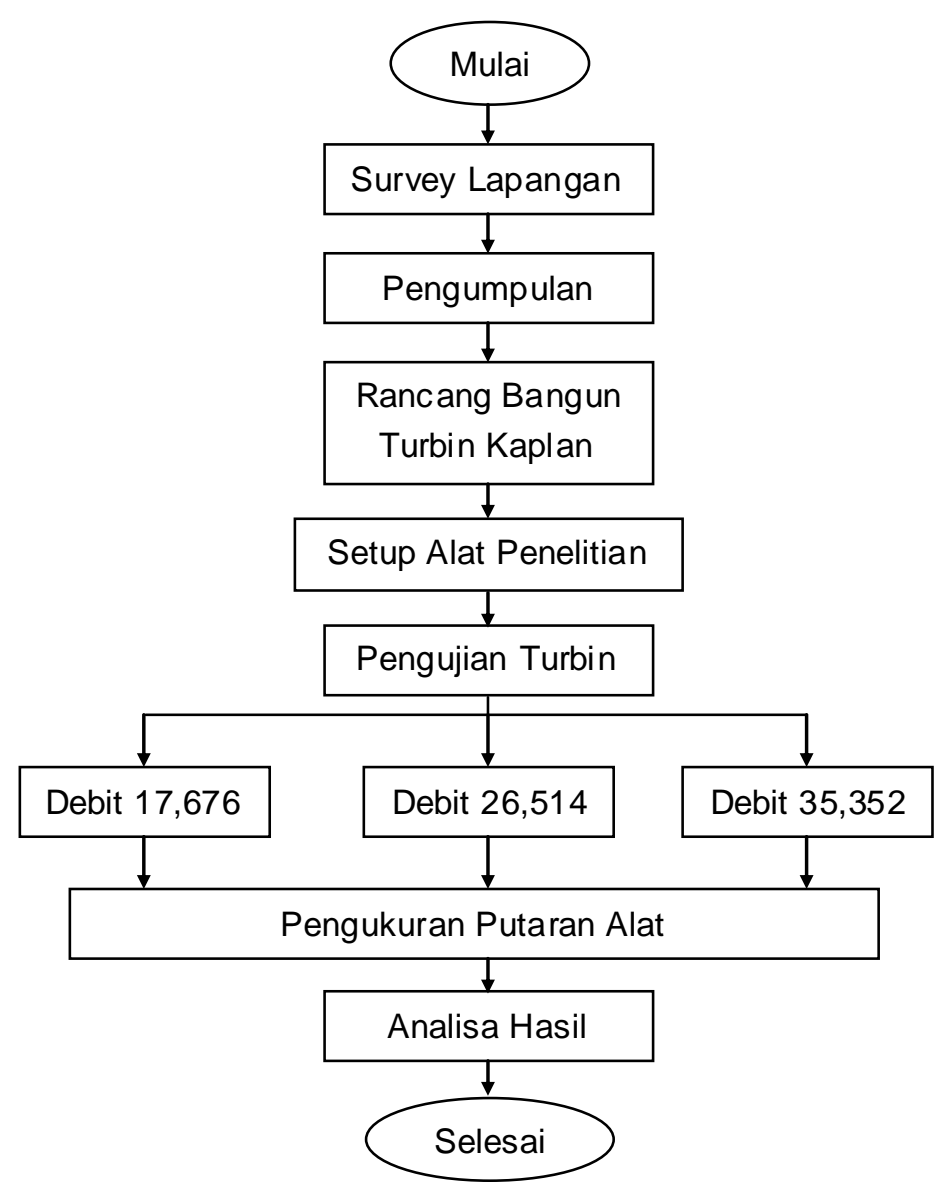

Gambar 6. Diagram Alir Penelitian

\section{B. Bahan dan Alat}

1. Bahan dan alat dalam penelitian

Alat yang di gunakan selama penelitian adalah sebagai berikut :
a. Hydrometer
b. Theodolith

2. Bahan dan alat dalam Pengujian
a. Tachometer
b. Stopwatch

\section{Tahapan Penelitian}

Tahapan penelitian ini adalah sebagai berikut:

1. Pastikan tidak ada kebocoran dalam instalasi percobaan

2. Pastikan air dalam kolam penampung air penuh

3. Pompa dalam keadaan terpasang dan siap untuk menaikan air dari kolam pnampumg air kebak turbin melalui pipa

4. Hidupkan pompa air 
5. Pada saat pompa 1 di hidupkan, yaitu pada debit $8,838 \mathrm{k} / \mathrm{s}$,turbin tidak berputar sehingga ditambah debit air dengan mnghidupkan pompa 2,3 dan pompa 4.

6. Ukur putaran turbin setiap pergantian debit air dengan tachometer

\section{HASIL DAN PEMBAHASAN}

Berdasarkan hasil pengujian putaran turbin kaplan pada sudu rotor $30^{\circ}$ dan sudu stator $30^{\circ}$ dengan variasi debit aliran air maka diperoleh sebagaimana terdapat pada tabel dan grafik dibawah ini:

Tabel 3. Data putaran hasil pengujian sudu rotor $30^{\circ}$ dan sudu stator $30^{\circ}$

\begin{tabular}{|c|l|l|c|}
\hline Sudu Rotor & $\begin{array}{l}\text { Sudu } \\
\text { Stator }\end{array}$ & Debit & $\begin{array}{l}\text { Putaran } \\
(\mathrm{rpm})\end{array}$ \\
\hline \multirow{3}{*}{$30^{\circ}$} & \multirow{3}{*}{$30^{\circ}$} & 17.676 & 136 \\
\cline { 3 - 4 } & & 26.514 & 205 \\
\cline { 3 - 4 } & & 35.352 & 503 \\
\hline
\end{tabular}

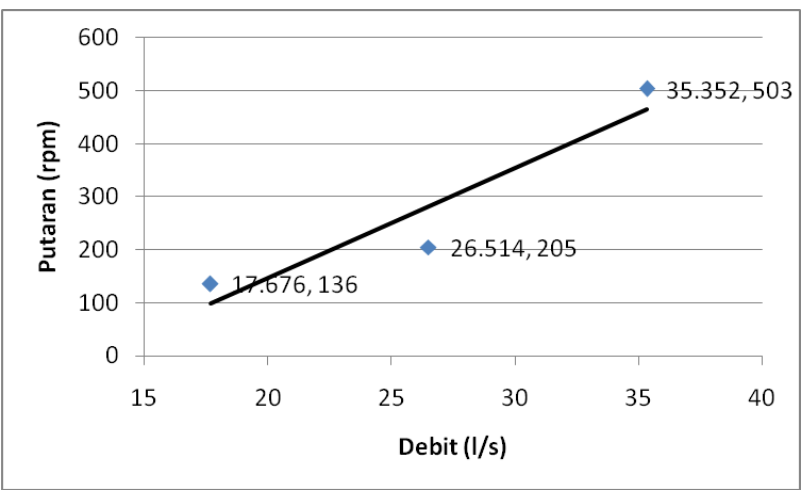

Gambar 7. Grafik hubungan putaran dengan debit pada sudu rotor $30^{\circ}$ dan sudu stator $30^{\circ}$

Pada gambar 7 diatas dapat dilihat bahwa penambahan debit air akan mengakibatkan perubahan putaran pada sudu rotor turbin, hal ini terjadi karena jumlah debit air yang bertambah mengakibatkan banyaknya air yang keluar dari sudu stator menuju pipa keluar semakin cepat karena massa air yang semakin besar dari penambahan debit aliran air tersebut dan tinggi jatuh air dari pipa keluar turbin yang menuju kebawah juga berpengaruh pada perubahan putaran pada sudu rotor. Dari hasil pengujian sudu rotor $30^{\circ}$ dan stator $30^{\circ}$ dengan variasi pengukuran debit aliran air 17,676 1/s - 35,532 1/s dihasilkan putaran turbin dengan putaran tertinggi $503 \mathrm{rpm}$ dan putaran terendah pada putaran $136 \mathrm{rpm}$.

\section{PENUTUP}

\section{Kesimpulan}

1. Dari hasil perancangan Turbin Kaplan dihasilkan diameter luar sudu turbin turbin 0,138 $\mathrm{m}$, diameter tengah sudu turbin $0,095 \mathrm{~m}$ diameter leher poros sudu turbin $0,057 \mathrm{~m}$, tinggi tuirbin $154 \mathrm{~cm}$, jumlah sudu 5 , sudut sudu rotor $30^{\circ}$ dan sudu stator $30^{\circ}$ 
2. Putaran tertinggi yang dihasilkan oleh Turbin Kaplan ini ada pada debit 35,352 1/s pada putaran503 rpm. Putaran terendah yang dihasilkan oleh Turbin Kaplan ini, ada pada debit 17,676 pada putaran $136 \mathrm{rpm}$.

3. Debit air yang di peroleh dari dari lapangan $\left(0,025 \mathrm{~m}^{3} / \mathrm{s}\right)$ tidak dapat memutar turbin.

\section{Saran}

1. Seblum melakukan pengoprasian tuirbin air , sebaiknya melakukan kalibrasi alat ukur sehingga tidak terjadi kesalahan dalam pengukuran

2. Dikarenakan penelitian ini hanya mencari putaran rotor maka perlu di lanjutkan dengan menggunakan generator untuk mlihat berapa watt listrik yang dhasilkan turbin ini,sehingga dapat diketahui torsi dan daya yang dihasilkan

\section{DAFTAR PUSTAKA}

Alfi Novaris, 2010. Modifikasi Rancang Bangun Pembangkit Listrik Tenaga Air Dengan Menggunakan Turbin Pelton (Tugas Akhir), UNDIP, Semarang.

Arismunandar, Wiranto., 1997, Penggerak Mula Turbin, ITB Bandung.

Dandekar, M. M., Sharma K.N., 1991, Pembangkit Listrik Tenaga Air, UI Press, Jakarta.

Dietzel, Fritz, 1996, Turbin, Pompa dan Kompresor, Erlangga, Jakarta.

Kadir, A., 1979, Mesin Arus Searah, Percetakan Aka.

Patty, I.F., 1995, Tenaga Air, Erlangga, Jakarta.

Sahid, dkk, 2006. Pengaruh Nozel Berpenampang Segi Empat Terhadap Unjuk Kerja Turbin Pelton Mikro Untuk Sistem Pembangkit Listrik Tenaga Mikrohidro, Forum Teknik POLINES, Semarang.

Sularso dan Suga, Kiyokatsu, 1995, Dasar-dasar Perencanaan dan Pemilihan Elemen Mesin, Pradnya Paramita, Jakarta.

Vasandani, V.P., 1984, Hidraulika Machines Theory and Design, Khanna Publishers, Delhi.

White, Frank M; Like Wilarjo, 1986, Mekanika Zalir, Erlangga, Jakarta. 